\title{
Training and Examinations for the Practice of Child and Adolescent Psychiatry
}

\author{
Michael H. Best, Senior Registrar, Maudsley Hospital
}

\section{A better training system}

The practice of child psychiatry depends upon clinical skills; the first requirement, then, of a training programme is that at the end of a given period the trainee should be really expert and rightly confident in his practical skills as a diagnostician and therapist. A total of four years, combining registrar and senior registrar experience, might be an appropriate period and would allow a full training, whereas at present some new consultants have spent only two and a half years in the specialty as senior registrars.

The clinical and academic curriculum should comprise extensive clinical experience in individual, marital, family, group and behavioural therapies, plus training in mental health consultation, as well as a full academic teaching programme in child development and child psychiatry. Useful additions to many training schemes would be study of the law, social work practice, adoption and fostering and the educational system, plus a more detailed study of mental handicap and psychology than is usual. Visits to the settings in which children live, play and work-the home, nurseries and schools-should be commonplace.

Child psychiatry requires a knowledge of paediatrics as well as psychiatry, but there is not the time, neither is it necessary, for a lengthy previous training in both of these. Eighteen months in adult psychiatry may be too long, on the other hand, six months in paedriatics might be made more widely available, not only does this afford knowledge of children's diseases but also insight into children's and parents' experience of hospital, and into the roles and functions of the paedriatrician. Training schemes, tailor-made for the individual, could well include posts in acute hospital paedriatrics or community child health or even general practice.

Conversely, there are paediatric trainees who would greatly appreciate a six-month period as registrars in child psychiatry-some might be potential excellent recruits to child psychiatry, and perhaps to the medical and psychiatric care of the mentally handicapped also.

Trainees in general adult psychiatry could be introduced to child psychiatry by part-time secondment on one or two half-days per week for a period of some months. Small groups of registrars could meet weekly with a teacher for case discussions. Paediatric trainees and perhaps those from other disciplines, for example clinical psychology, general practice or social work, might well join such a group. Most adult psychiatry candidates would find their examination needs covered in this way, as well as learning something of value for their own later clinical practice.

Those who develop a special interest in child psychiatry, whether they be drawn from paediatrics or general psychiatry, could then opt for a short full-time registrar post in child psychiatry to test out their own interest further in the subject, and their suitability for further training could then be discreetly assessed. Those then accepted at registrar level into a child psychiatry training programme could, at the start, have a personalized curriculum drawn up which would take account of their previous experience. This would give the trainee a clear guide of what he or she would be expected to learn and what clinical skills he or she should hope to acquire over the next three to four years. If, as I suggest later, the College were to create a special examination in child and adolescent psychiatry, the transition from registrar to senior registrar would be made after obtaining the appropriate qualification. There is no reason why similar specialist diplomas could not be instituted for psychiatric social workers and clinical psychologists and, indeed, the greater part of the clinical and academic training could be shared with the psychiatric trainees.

At senior registrar level the higher trainee would be well equipped to handle greater responsibility with confidence, to extend his academic base, to begin to teach others and to start his own research. Furthermore, he or she could opt for a further degree of specialization, that is, in child psychiatry, adolescent psychiatry or the psychiatry of mental handicap in childhood.

\section{A College examination in child paychiatry?}

In my view the College should consider the notion of an examination with appropriate training requirements in child psychiatry, leading to Membership. This would be akin to the relatively recently established paediatric option for Membership of the Royal College of Physicians. Alternatively there could be a new Diploma in Child and Adolescent Psychiatry. Child psychiatry specialist training could then start at the registrar stage rather than the senior registrar level.

For the trainee who gains a year's exemption for relevant other experience, the current MRCPsych regulations permit a candidate to sit the Membership examination after only two years in psychiatry, though six months of this may be in one of the specialities. Clearly a new examination in child psychiatry would have to have comparable requirements, that is, two years in child and adolescent psychiatry. A further year in adult psychiatry or other acceptable speciality, for example, a branch of paedriatrics, mental handicap or general practice would be needed if the qualification to be awarded remained solely Membership of the College.

If a Diploma examination subsequent to gaining the MRCPsych were considered more appropriate so that the child psychiatrist had greater experience, that is, eighteen months of adult psychiatry, then it would be possible for time spent in child psychiatry for the MRCPsych to count towards the Diploma also. Such a double qualification system would allow those who decide early on to become 
child psychiatrists to plan their studies to avoid unnecessary time in other specialties, and those who make this career choice later would be able to switch easily. It is neither possible nor desirable for all trainees to pursue identical training programmes.

A scheme such as the one proposed could take a new consultant to a relatively advanced stage of expertise in the field of clinical child psychiatry. An examination in child psychiatry, taken after two years in the specialty at registrar grade, would allow specialist accreditation (if adopted for this specialty) at the end of higher professional training, that is, as senior registrar, without the need for an examination at this late stage. As part of the Preliminary Test, an oral examination could be taken after, say, a year in child psychiatry, which would provide independent College assessment of the candidate's suitability for the specialty apart from that of his or her own training centre. In the Membership or Diploma examination use might be made of oral discussion of selected case histories compiled by the candidate from amongst those he had personally treated, and the candidate's video-taped family therapy sessions. This last suggestion would help to ensure the availability of video equipment and its use for supervision and self-observation for all trainees.

\section{Parliamentary News}

\section{(January-April, 1981)}

\section{Registration of paychotherapiets}

On 15 April Mr Graham Bright introduced his Private Member's Bill, described as 'a Bill to create a Council for Psychotherapy, with power to maintain a register of practitioners and to enforce a code of ethics'. Mr Bright laid stress on the need to protect the public against exploitation by charlatans. He claimed that the proposals of the Sieghart working party, on which the Bill was based, rested on a wide measure of agreement between professional bodies in which he included the Royal College of Psychiatrists.

Mr Stan Thorne opposed the introduction of the Bill, mainly on the ground that it went beyond the Sieghart recommendations, giving the proposed Council power to proscribe the use of psychotherapy by unqualified persons.

Leave to introduce the Bill, was, however, given, as no one offered to act as Teller for the 'Noes'. No view was expressed on behalf of the Government.

\section{Mental Health Services}

\section{Debate}

On 31 March the Earl of Longford initiated a debate on mental after-care. He and subsequent speakers went over the well-trodden ground of community care policy frustrated by inadequate provisions and facilities, and very little was said that could not have been quoted from previous debates. Lord Richardson told the House that he had been in consultation with Professor Wing and Sir Desmond Pond about the points that seemed to them of particular importance; his speech consisted for the most part of a brief outline of the needs of mental hospital patients according to their length of stay. He drew attention to the College's report Rehabilitation in the 1980s, and to the experimental 'bed-hostel' at the Maudsley Hospital. Other speakers were Lord Winstanley (from a GP's point of view), Lord Lloyd (voicing the predicaments of voluntary bodies), Baroness Masham (concerned mainly with the mentally handicapped), Lord
Taylor of Gryfe (describing the work of 'Link' in Glasgow), Lord Auckland, Lord Soper, the Countess of Loudoun (closer liaison between housing, employment and social work agencies, and praising MIND's 'Home from Hospital' campaign of 1976), Baroness Faithfull, and Lord Wallace of Coslany. Lord Cullen of Ashbourne, for the Government, gave the usual departmental reply, quoting various figures showing what developments have in fact taken place. He did, however, suggest a minor change of policy whereby 'the fixed White Paper guidelines' might be replaced by a range of guidelines which discriminate between high need and low need localities. He, too, commended the College's Rehabilitation report.

Some of the figures given are as follows, though the relevant years are not always the same:

Residential places up from 332 to 5,604

Day hospital places up from 10,200 to 13,000

Local authority day centres up from 5,374 to 7,740

Community psychiatric nurses up to 2,000

Grants to local authorities for mental illness up by 58 per cent in real terms.

\section{Questions}

Figures for revenue expenditure on the mental health services were given on 20 January. The proportion of total NHS funds spent on mental handicap over the last five years has remained approximately constant at 3.8 per cent in both England and Scotland; for mental illness it has also been constant, in England at about 8.3 per cent and in Scotland at about 10.6 per cent.

Suicides in psychiatric hospitals and departments fluctuated between 73 and 93 annually in the years 1971-76, but increased to 127 in 1978 .

It was stated on 20 January that the DHSS's policy was to expand the consultant grade faster than the training grades, but that so far implementation had been slow. 